\title{
Possibilities for Use of Coal Bed Methane \& Coal Bed Mine in Asturias ${ }^{+}$
}

\author{
Pablo Cienfuegos-Suárez *, Diego Alonso-Fernández and Efrén García-Ordiales \\ Department of Mining Exploitation and Prospecting, University of Oviedo, 33004 Oviedo, Spain; \\ dafasturias@hotmail.com (D.A.-F.); garciaefren@uniovi.es (E.G.-O.) \\ * Correspondence: cienfuegospablo@uniovi.es; Tel.: +34-985-10-4223 \\ † Presented at the 2nd International Research Conference on Sustainable Energy, Engineering, Materials and \\ Environment (IRCSEEME), Mieres, Spain, 25-27 July 2018.
}

Published: 2 November 2018

\begin{abstract}
There is a number of risk issues associated with CBM/CMM operations: sealing the mine shafts; pumping the mine water; evacuating air from the mine and air ingress into the mine. Our team has investigated the details of the initial phase of the business plan and, by extrapolation of key parameters, was able to form an opinion on the larger plan. The details investigated include: the methods to calculate the volume of gas entrapped in the coal; the sealing of the mine shafts to trap the gas escape; and the process to keep the mines pumped dry by removing the underground water that drains into the mine workings.
\end{abstract}

Keywords: Cleats; coal; Asturian basin

\section{Introduction}

Asturias Central Coal Basin (ACCB), located in Northern Spain, is the most important one in the Iberian Peninsula and some antecedents for coalbed methane exploration on this basin go back to the beginning of the 90's, when two deep drills have been made in selected areas of the Central Coal Basin (Figure 1).

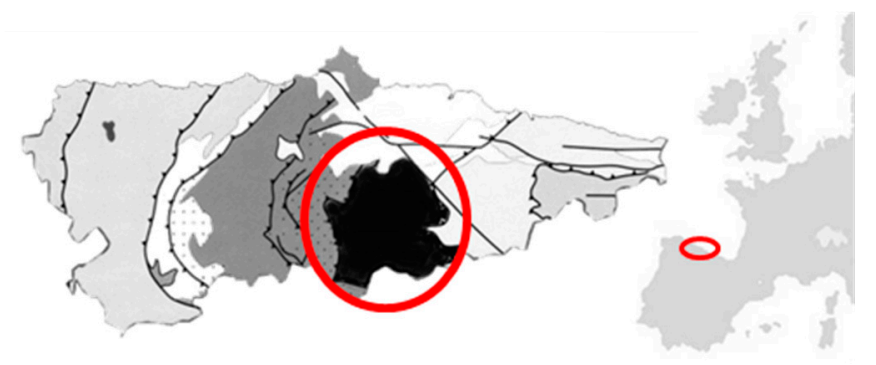

Figure 1. Location of the Asturian Central Carboniferous Basin.

This abstract contains preliminary studies, accomplished from 2003 to 2016, on the productive carboniferous potential of the Asturian Central Coal Basin for the development of coalbed methane projects. According to these studies, the gas content in coal beds approximately ranges from 3.9 to $10.8 \mathrm{~m}^{3} / \mathrm{t}$, and the minimum value of coalbed methane resources in the Asturian Central Coal Basin has been estimated in 25,000 $\mathrm{Mm}^{3}$ [1].

Despite the fact that the gas content in the entire coal basin is modest, it appears to be adequate for a commercial coalbed methane development, although it is limited by the size of the basin [2].

The option for implementation of coalbed methane projects in this basin is associated not only with carbon dioxide sequestration in unexploited coal beds, but also with the application of a 
non-traditional coalbed methane development programme, including the use of directional drilling from a limited number of well sites.

\section{Details of the Business Plan}

The business plan starts with a first phase, to develop a CBM/CMM operation at the Maria Luisa-Pumarabule (M-P) mines. The project will convert the gas produced from the abandoned mine workings to electricity on site, and transfer sales to the electrical grid.

The coal seam areas are characterized differently, depending on the mining activity that has been undertaken. The areas that have been mined are referred to as destressed, and the unmined areas as stressed.

The $\mathrm{CBM} / \mathrm{CMM}$ gas production is derived from the methane that seeps from the remaining coal seams in the mine complex.

The methane gas is stored in the coal measures in a different manner from conventional natural gas reservoirs, such as sandstone. The hydrocarbon gas is located within the micro pores of the coal matrix as a physically adsorbed layer and, because of this, the coal can contain much more methane per unit volume than a sandstone or similar reservoir.

The estimation of the CMM gas reserves and gas production rates, the production at M-P will be sufficient to power three 1.3 KVA gas powered generators (Generator Sets). These can produce a total $4 \mathrm{MW}$ of electricity.

There is a number of risk issues associated with CBM/CMM operations: sealing the mine shafts; pumping the mine water; evacuating air from the mine and air ingress into the mine. The introduction should briefly place the study in a broad context and define the purpose of the work and its significance.

\subsection{Sealing the Mine Shafts}

There are four mineshafts in the M-P mine to be sealed, and a total of 45 within the area. The seals are concrete slabs to be anchored into the existing concrete mine shaft walls. This forms a strong reinforced plug and seal. At the pump location mineshaft will install two casing risers for new water pumps. The purpose of the pumps is explained in the next section. The risers will pass through the cement plug. A gas-tight manhole will also be installed for access to the sealed mine.

\subsection{Pumping the Mine Water}

Many mines in England and Germany are affected by underground water influx and the same situation as exists in the ACCB area in Spain. All these mines have historically required a water removal system to support mining activity. When the mines are abandoned, all the underground water pumping stops. The mines elsewhere are allowed to flood to prevent methane production into the atmosphere. This water has the effect to inhibit the gas desorption process within the coal seams. It can subsequently take years to drain a mine system, and to get the gas desorption process to start again. For the company, the mine flooding after abandonment has been avoided in the Asturias Mining area. For example, the abandoned M-P mine continues to pump out the mine waters such that the mine workings remain un-flooded; this facilitates the CMM operations.

At present, HUNOSA has a complete water management system in place that relies on positive displacement mine pumps. At M-P, the pumping system is located at a depth of $592 \mathrm{~m}$ in shaft No. 2 . Fresh water flow rates have been monitored, and the company has determined, based upon the existing pump capacity, that the maximum flooding rate during the rainy season has not exceeded $37 \mathrm{~L} / \mathrm{s}(20,000 \mathrm{bbl} /$ day). The flow is typically much less in the dry season.

The peak volumes and the hydrostatic head dictated the pump design and power requirements. The design has been optimized by using two variable speed $192 \mathrm{HP}$ pumps with a nominal $20 \mathrm{~L} / \mathrm{s}$ capacity. The pumps are able to decrease or increase the pumped volumes by frequency changes. The pump rates can range from less than 10 up to more than $25 \mathrm{~L} / \mathrm{s}$. This allows both pumps to run 
continuously, but as they will operate at a lower power output for most of the year, this will extend the pump life.

\subsection{Evacuating Air from the Mine}

Once the mine is sealed and the new water pump system installed, it will be necessary to evacuate the air from within the mine prior to undertaking CMM production. A Siemens Water Jacket ELMO pump will be used to accomplish the mine evacuation. During the conversion from air to gas, the mixture becomes highly combustible at some stage, and the Siemens pump can handle this safely. Based upon the mine volumes and pump rates, and the experience of other CMM operations in Germany, we have determined that this process could take three months. It is intended to flare the unusable air-gas mixture (a normal process) until the methane concentration is of sufficient quality to start powering the Generator Sets.

\subsection{Air Ingress into the Mine}

Another issue that frequently affects abandoned mines is the possible air ingress through formation outcrops, or other permeable paths to the surface. This situation requires careful monitoring, and in some cases, it requires remedial sealing of the leak at the surface.

This helps to maintain the mine gas quality, and to retain the partial pressure within the mine that is necessary for the CMM operations. The M-P mine complex is overlain with a natural mountain area which provides a barrier to such gas seepage, or the air ingress. The unknown permeable conduits underground in the up heaved geological structures could still be a problem. At the M-P mine area, there is one identified small surface seep off the edge of the mountain area. The methane from the seep burns in a display grotto with a flame about the size of a candle.

To remedy any significant ingress paths that are detected in the course of the CMM development, the company has located a company that offers the services to seal such paths. GCA considers the air ingress to be an insignificant risk at the M-P mine. There is a natural seal above the mine provided by the surface mountain area that will mitigate the risk.

\subsection{Generator and Plant Requirements}

The Generator Set modules include more equipment than just the CMM powered motor and electric generator. These modules include: the blower station necessary to maintain the mine partial pressure for CMM production; and the generator transformer. In addition, the generators feed a medium voltage transformer station connected to the grid.

\subsection{Electric Grid Connection}

At each site, the previous mining operations had required, and installed, a high voltage electric transmission system. This system remains in place and is capable of handling the expected electricity output of the generation plant.

\section{Methodology for Estimating CMM Reserves and Future Methane Production}

\subsection{Coal in Place and Coal Remaining}

We reviewed the company's coal mine information database for the Mieres License area and examined in detail the work performed to determine the original coal in place. The original coal in place was determined from data taken from the mining survey records that identify the individual coal seams, their dimensions and the extent of any workings throughout the mine area. The mine records provide accurate information for the volume of the excavation, and the amount of coal removed from a worked seam.

The near vertical coal seams contrast with the more normal flat coal seams that exist elsewhere. However, the volumetric procedures completed by us are reasonable and form a solid foundation for the gas resource assessment in this area. 


\subsection{Gas in Place}

To convert from the coal volumes to gas volumes, it is necessary to utilize parameters that account for the gas content in coal.

The relationship differs for different coal types and it is normally determined experimentally on actual coal samples. By applying the isotherm equation for the CMM process, and by knowing the coal seam pressure, the gas volume adsorbed in the coal is determined. In the CMM production, the pressure is lowered by a suction process and causes more gas production within the coal seams. The equations define how much gas the coal will hold at the lower pressure. The difference in the two volumes between two pressure values determines how much gas is released or produced.

No coal samples from M-P have been analysed to determine their Langmuir Isotherm, but several samples were collected by Union Texas Petroleum during the drilling of their nearby Asturias\#1 well. This was a coal bed methane (CBM) operation drilled in the 1990s.

The gas content, corrected for ash and moisture content data, was correlated to depth below ground level. The coal seams at the mine depths contained 8 to $10 \mathrm{~m}^{3} / \mathrm{t}$ of gas. From this data, it was possible to construct a synthetic Langmuir Isotherm for the coal of the area.

\subsection{Gas Recovery and Production Rates}

The determination of the gas recovery factor for the CMM process was achieved by considering it in two parts: (i) the depletion of the coal seams during the mining period (mining phase); and (ii) the time during which the gas is produced from the mines under CMM operations.

The CMM production rates were determined from the simulations and these were substantiated by comparing the forecasts with the extrapolation of the results from a series of gas samples (methane \%) taken at the surface (these showed variations with ambient pressure) of the inactive M-P mine. The analysis showed small changes in methane concentration with pressure could be extrapolated to the 0.5 bar coalface pressure. The analysis predicts that the initial production from the M-P mine could approach $3.5 \mathrm{MMcfd}$. This is very similar to the rates seen in existing CMM operations elsewhere in Europe. It is also more than three times the volume required for the three 1.3 MW Generator Sets envisioned for the M-P development. For further conservatism, the company has modelled the gas production decline using a hyperbolic method.

\subsection{Reserves Volumes}

Three different reserves categories have been reviewed: proved; proved and probable; proved probable and possible. Deterministic methods were used to define the different reserve categories. The methods were established to meet the required certainty criteria for the producible gas for each reserve category. The controlling factors for the gas production simulation were: the volumes of coal seams in or near the bubble areas; the duration of the original mining operations which created the deformation bubbles; the gas loss; and the permeability of the coal seams.

The Proved Undeveloped (PUD) reserves were based on the volumes recovered from the low permeability coal in the bubble areas. The simulation shows that recoveries in this environment are in the range of $20 \%$ of the original gas in place for the areas less than $500 \mathrm{~m}$ from the mine shaft.

The Probable reserves allow for an incremental increase in the permeability within the bubble area over the PUD. In addition, the Probable reserves account for some gas recovery from an area of coal seams, up to $500 \mathrm{~m}$ either side, outside the deformation bubble. The Possible reserves include a further incremental gas within the bubble area which could exist for the shorter mine times (10 year) and which retain a higher permeability. Additional Possible reserves include the remaining coal seams outside the "bubble" with the lower permeability, which were not included in the Probable reserves (Table 1). 
Table 1. CMM Reserves of the ACCB Coal Mines.

\begin{tabular}{cccc}
\hline Mine Complex & Proved Undeveloped (Bcf) & Probable (Bcf) & Possible (Bcf) \\
\hline María Luisa & 5.2 & 1.9 & 5.7 \\
M-P & 2.8 & 1.9 & 6.2 \\
Sta. Bárbara & 1.1 & 0.8 & 2.6 \\
Aller & 3.3 & 2.8 & 9.2 \\
Barredo & 2.2 & 1.3 & 4.4 \\
San Mamés & 0.8 & 0.7 & 2.4 \\
Fondón & 2.7 & 1.9 & 6.2 \\
Total & 18.1 & 11.3 & 36.7 \\
\hline
\end{tabular}

The reserve estimates presented are based on the definitions of reserve categories of Society of Petroleum Engineers (SPE) and World Petroleum Congresses (WPC) and are widely used in the petroleum industry.

The total planned gas production during the CMM operations in the area is $25 \mathrm{Bcf}$. This represents just over $1 \%$ of the original gas in place (1.9 Tcf) trapped in the coal seams.

\section{Conclusions}

The business possibility of electricity production through CBM/CMM of the Asturian mines is a real and advantageous possibility for the company that decides to invest. Currently there is no company that has developed the possibilities of the CBM/CMM at production level.

Author Contributions: P.C.-S., D.A.-F. and E.G.-O. contributed to the design and implementation of the research, to the analysis of the results and to the writing of the manuscript.

Conflicts of Interest: The authors declare no conflict of interest. The founding sponsors had no role in the design of the study; in the collection, analyses, or interpretation of data; in the writing of the manuscript, and in the decision to publish the results.

\section{References}

1. Pendás Fernández, F.; Zapatero Rodríguez, M.Á.; Loredo Pérez, J. Reunión Científico-Técnica sobre Exploración, Evaluación y Explotación del Metano de las Capas de Carbón. Oviedo 23-25 de Mayo de 2001; Instituto Geológico y Minero de España: Madrid, Spain, 2002.

2. Cienfuegos, P.; García, R.; García-Ordiales, E. Aplicación de la hidroquímica en la prospección preliminar de metano de carbón en la Cuenca Carbonífera Asturiana. In Proceedings del IX Congreso Geológico de España, Huelva, Spain, 12-14 September 2016; pp. 467-471. 